\title{
Activation of Peripheral and Central Trigeminovascular Neurons by Seizure: Implications for Ictal and Postictal Headache
}

\author{
Agustin Melo-Carrillo, ${ }^{1,2}{ }^{\circledR}$ Aaron J. Schain, ${ }^{1,2}$ Andrew M. Strassman, ${ }^{1,2}$ and ${ }^{-}$Rami Burstein ${ }^{1,2}$ \\ ${ }^{1}$ Department of Anesthesia, Critical Care and Pain Medicine, Beth Israel Deaconess Medical Center, Boston, Massachusetts 02115, and ${ }^{2}$ Harvard \\ Medical School, Boston, Massachusetts 02215
}

An epileptic seizure can trigger a headache during (ictal) or after (postictal) the termination of the event. Little is known about the pathophysiology of seizure-induced headaches. In the current study, we determined whether a seizure can activate nociceptive pathways that carry pain signals from the meninges to the spinal cord, and if so, to what extent and through which classes of peripheral and central neurons. To achieve these goals, we used single-unit recording techniques and an established animal model of seizure (picrotoxin) to determine the effects of epileptic seizure on the activity of trigeminovascular A $\delta$-, C-, wide-dynamic range, and high-threshold neurons in male and female rats. Occurrence of seizure activated $54 \%, 50 \%, 68 \%$, and $39 \%$ of the A $\delta$-, C-, wide-dynamic range, and high-threshold neurons, respectively. Regardless of their class, activated neurons exhibited a twofold to fourfold increase in their firing, which started immediately $(1 \mathrm{~min})$ or up to $90 \mathrm{~min}$ after seizure initiation, and lasted as short as $10 \mathrm{~min}$ or as long as $120 \mathrm{~min}$. Administration of lidocaine to the dura prevented activation of all neuronal classes but not the initiation or maintenance of the seizure. These findings suggest that all neuronal classes may be involved in the initiation and maintenance of seizure-induced headache, and that their activation patterns can provide a neural substrate for explaining the timing and duration of ictal and possibly postictal headaches. By using seizure, which is evident in humans, this study bypasses controversies associated with cortical spreading depression, which is less readily observed in humans.

Key words: headache; ictal headache; postictal headache; seizure; trigeminovascular system

\section{Significance Statement}

This preclinical study provides a neural substrate for ictal and postictal headache. By studying seizure effects on the activity of peripheral $(\mathrm{C}$ and $\mathrm{A} \delta$ ) and central (wide dynamic range and high-threshold) trigeminovascular neurons in intact and anesthetized dura, the findings help resolve two outstanding questions about the pathophysiology of headaches of intracranial origin. The first is that abnormal brain activity (i.e., seizure) that is evident in human (unlike cortical spreading depression) gives rise to specific and selective activation of the different components of the trigeminovascular system, and the second is that the activation of all components of the trigeminovascular pathway (i.e., peripheral and central neurons) depends on activation of the meningeal nociceptors from their receptors in the dura.

\section{Introduction}

Epilepsy is a common neurologic disorder globally, with a lifetime prevalence of 7.69 per 1000 persons (95\% CI, 6.17-9.38) with incidence of 61 per 100,000 person-years (95\% CI,

\footnotetext{
Received Feb. 5, 2020; revised Apr. 12, 2020; accepted Apr. 15, 2020.

Author contributions: A.M.-C., A.M.S., and R.B. designed research; A.M.-C. performed research; A.M.-C., A.M.S., and R.B. analyzed data; A.M.-C. and R.B. wrote the first draft of the paper; A.M.-C., A.J.S., A.M.S., and R.B. edited the paper; A.M.-C., A.M.S., and R.B. wrote the paper.

This work was supported by National Institutes of Health Grants R37-NS079678, R01 NS069847, and R01 NS094198 to R.B.

The authors declare no competing financial interests.

Correspondence should be addressed to Rami Burstein at rburstei@bidmc.harvard.edu.

https://doi.org/10.1523/JNEUROSCI.0283-20.2020

Copyright $\odot 2020$ the authors
}

50.75-74.38), and has one of the highest disability-adjusted life years among neurologic disorders (Zarrelli et al., 1999; Murray et al., 2012; Ablah et al., 2014; Fiest et al., 2017). Over 50\% of patients have focal epilepsy; and of the subset with refractory seizures, only $\sim 10 \%-20 \%$ of patients undergo epilepsy surgery (Sanchez Fernandez et al., 2017). Patients with medically refractory epilepsy are at increased risk of sudden unexplained death in epilepsy, with a high lifetime burden of frequent generalized tonic clonic seizures further elevating this risk (Verducci et al., 2019).

The association between seizures and migraine is well established (Leniger et al., 2001; Forderreuther et al., 2002; KaraaliSavrun et al., 2002; Kwan et al., 2008; Cianchetti et al., 2013) and widely recognized by the International Classification of Headache 
A

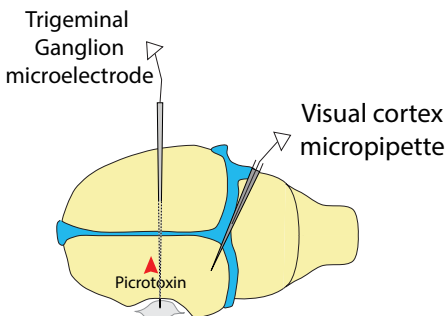

B

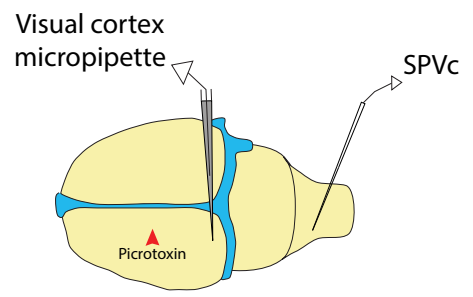

care and were in accordance with the National Institutes of Health's Guide for the care and use of laboratory animals.

\section{Surgical preparation}

Male and female Sprague Dawley rats (250-340 g) were anesthetized with urethane $(0.9-1.2 \mathrm{~g} / \mathrm{kg}$, i.p.). They were fitted with an intratracheal tube to allow artificial ventilation $\left(0.1 \mathrm{~L} / \mathrm{min}\right.$ of $\left.\mathrm{O}_{2}\right)$ and an intrafemoral vein cannula for later infusion of drugs. Rats were placed in a stereotaxic apparatus, and core temperature was kept at $37^{\circ} \mathrm{C}$ using a heating blanket. End-tidal $\mathrm{CO}_{2}$ was monitored continuously and kept within physiological range (3.5$\left.4.5 \mathrm{pCO}_{2}\right)$. Once stabilized, rats were paralyzed with rocuronium bromide $(10 \mathrm{mg} / \mathrm{ml}, 2.1 \mathrm{ml} / \mathrm{h}$ continuous intravenous infusion) and ventilated.

In all experiments, for stimulation of the cranial dura later in the experiment, a $5 \times 5 \mathrm{~mm}$ opening was carefully carved in the parietal and occipital bones in front and behind the $\lambda$ suture directly above the left

Disorders Committee, which attributes two different headaches to epileptic seizure, ictal and postictal. Ictal epileptic headache is a headache caused by and occurring during a partial epileptic seizure, ipsilateral to the epileptic discharge and remitting immediately or soon after the seizure has terminated (Headache Classification Committee of the International Headache Society, 2018). This condition may be followed by other epileptic manifestations involving motor, sensory, or autonomic networks (Yankovsky et al., 2005; Syvertsen et al., 2007). Postictal headache is a headache by and occurring within $3 \mathrm{~h}$ after an epileptic seizure, and remitting spontaneously within $72 \mathrm{~h}$ after seizure termination (Headache Classification Committee of the International Headache Society, 2018). It affects $12 \%-36 \%$ of pediatric patients and $30 \%-50 \%$ of adult patients. It occurs in over $40 \%$ of patients with either temporal lobe epilepsy or frontal lobe epilepsy and in up to $60 \%$ of patients with occipital lobe epilepsy. It is more frequent after generalized tonic-clonic seizures than other seizure types (Schon and Blau, 1987; Ito et al., 2004; Botha et al., 2010). In clinical practice, however, patients with epilepsy frequently complain of headache but primarily seek treatment for the seizure. As a result, physicians tend to focus on the treatment of the seizure rather than on the headache, which is considered less risky. Although less risky, postictal headache can last many hours; and since it strikes repetitively, it causes patients to endure a significant hardship.

The goal of this study is to investigate the mechanism by which seizure might induce headache, by examining the effect of seizure on the activity of primary afferent (trigeminal ganglion) and second-order (dorsal horn) trigeminovascular neurons. The trigeminovascular system is the sensory pathway that provides the innervation to the intracranial meninges, and is thought to be involved in the generation of migraine headache (Moskowitz, 1984; Strassman et al., 1996; Burstein et al., 2015). Previous studies have shown that trigeminovascular neurons become activated following the induction of cortical spreading depression (CSD), a type of cortical disturbance that has been implicated in the migraine aura. By examining the effect of seizure, the present study goes beyond CSD in exploring further the relationship between cortical pathophysiology and the trigeminovascular system.

\section{Materials and Methods}

Experiments were approved by the Beth Israel Deaconess Medical Center and Harvard Medical School standing committees on animal

transverse sinus. The exposed dura was kept moist using a modified synthetic interstitial fluid containing the following (in $\mathrm{mM}$ ): 135 $\mathrm{NaCl}, 5 \mathrm{KCl}, 1 \mathrm{MgCl}_{2}, 5 \mathrm{CaCl}_{2}, 10$ glucose, and 10 HEPES, pH 7.2. A second craniotomy ( $\sim 2.2 \mathrm{~mm}$ diameter) was carefully carved immediately caudal to the left coronal suture (parietal cortex), and the cortex was exposed by removal of the dura to induce epileptiform activity by topical application of picrotoxin.

\section{Peripheral recordings}

In experiments in which recordings were made from peripheral neurons in the left trigeminal ganglion, a craniotomy was made on the right (contralateral) side to allow the microelectrode to be advanced through the contralateral cortex to reach the ganglion, using an angled approach. This was done to avoid damage to the ipsilateral cortex. The craniotomy was made to allow electrode insertions into the right cortex covering an area of 1-3 mm caudal to bregma and $1.5-3 \mathrm{~mm}$ lateral. The dura covering this area of cortex was removed to allow microelectrode insertion.

\section{Central recordings}

In experiments in which recordings were made from central neurons in the left C1-C2 dorsal horn (spinal trigeminal nucleus [SpV]), a segment of the spinal cord between the obex and $\mathrm{C} 2$ was uncovered from overlying tissues, stripped of the dura mater, and kept moist with synthetic interstitial fluid.

Experiments were only performed in cases in which the physiological condition of the rats (heart rate, blood pressure, respiration, end-tidal $\mathrm{CO}_{2}$ ) and the neuronal isolation signal (signal-to-noise ratio $\sim 1: 3$ ) were stable throughout the experimental period. At the conclusion of all central experiments, a small lesion was produced at the recording site (anodal DC of $15 \mu \mathrm{A}$ for $15 \mathrm{~s}$ ), and its localization in the dorsal horn was determined postmortem using histologic analysis as described previously (Zhang et al., 2011). Only one neuron was studied in each animal.

\section{Identification and characterization of peripheral and central trigemino- vascular neurons}

Peripheral recordings. A platinum-coated tungsten microelectrode (impedance 150-300 k $\Omega$ ) was advanced into the trigeminal ganglion for single-unit recording (Fig. $1 A$ ). To reach the ganglion via a contralateral approach, the electrode was angled medially $21^{\circ}$ and was advanced through the contralateral cortex (see above for coordinates). Dural afferent neurons in the ganglion were identified by their constant latency response to single-shock stimulation delivered to the dura overlying the ipsilateral transverse sinus with a bipolar stimulating electrode $(0.5 \mathrm{~ms}$ pulse, $5 \mathrm{~mA}, 0.75 \mathrm{~Hz}$ ). The response latency was used to calculate conduction velocity, based on a conduction distance to the trigeminal ganglion of $12 \mathrm{~mm}$. Neurons were classified as either A $\delta$ units (conduction velocity $1.5-5 \mathrm{~m} / \mathrm{s}$ ) or $\mathrm{C}$ units (conduction velocity $<1.5 \mathrm{~m} / \mathrm{s}$ ). Neurons with conduction velocity $>5 \mathrm{~m} / \mathrm{s}$ were not studied. Spike 2 software 


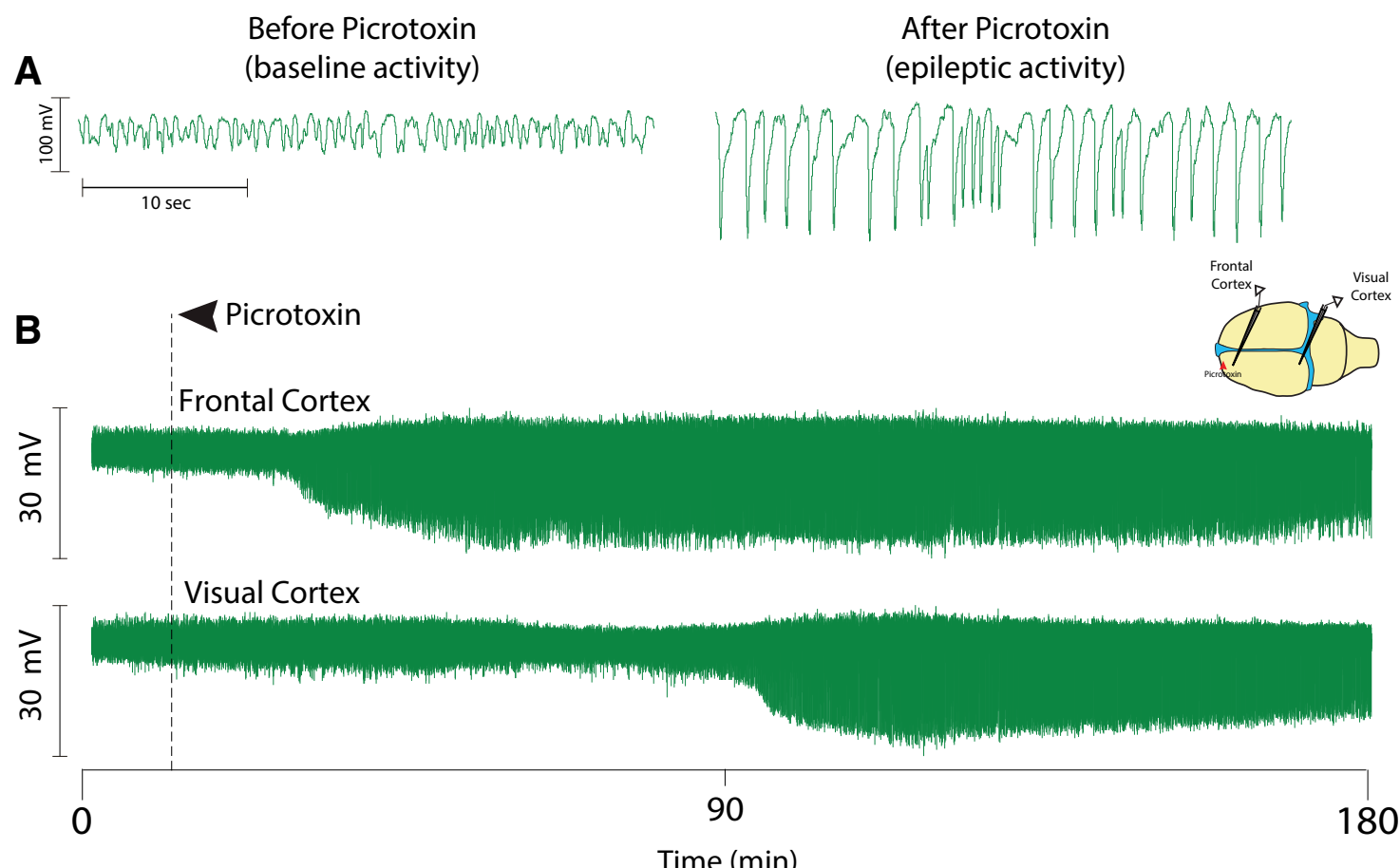

Time (min)

Figure 2. A, Normal (before picrotoxin) and epileptiform cortical activity (after picrotoxin). B, Propagation of epileptic cortical activity from the frontal to the visual cortex.

(Cambridge Electronic Design) was used for acquisition and waveform discrimination of the electrically evoked spikes, and for offline analysis. Mechanical receptive fields of dural afferents were identified by probing the dura with a von Frey hair $(4.19 \mathrm{~g})$. Only neurons for which a mechanical receptive field could be identified were selected for study.

Central recordings. To record neuronal activity, a tungsten microelectrode (impedance 1-4 $\mathrm{m} \Omega, \mathrm{FHC}$ ) was lowered repeatedly into the SpV (C1-C2 dorsal horn) in search of central trigeminovascular neurons receiving input from the dura (Fig. 1B). Trigeminovascular neurons were first identified based on their responses to electrical stimulation of the dura. They were selected for the study if they exhibited discrete firing bouts in response to ipsilateral electrical (0.1-3.0 mA, $0.5 \mathrm{~ms}, 0.5 \mathrm{~Hz}$ pulses) and mechanical (with a calibrated von Frey monofilaments) stimulation of the exposed cranial dura.

Dural receptive fields were mapped by indenting the dura (4.19 g von Frey hair monofilament). Points at which dural indentation produced a response in $>50 \%$ of the trials were considered inside the neurons' receptive field. Cutaneous receptive fields were mapped by applying innocuous and noxious mechanical stimulation to all facial skin areas as described previously (Burstein et al., 1998). An area was considered outside the receptive field if no stimulus produced a response in $>50 \%$ of the trials. Responses to mechanical stimulation of the skin were determined by applying brief (10 s) innocuous and noxious stimuli to the most sensitive portion of the cutaneous receptive field. Innocuous stimuli consisted of slowly passing a soft bristled brush across the cutaneous receptive field (one $5 \mathrm{~s}$ brush stroke from caudal to rostral and one $5 \mathrm{~s}$ brush stroke from rostral to caudal) and pressure applied with a loose arterial clip. Noxious stimuli consisted of pinch with a strong arterial clip (Palecek et al., 1992; Dado et al., 1994; Burstein et al., 1998). More intense or prolonged stimuli were not used to avoid inducing prolonged changes in spontaneous neuronal discharge or response properties. Two classes of neurons were thus identified: widedynamic range (WDR) neurons (incrementally responsive to brush, pressure, and pinch) and high-threshold (HT) neurons (unresponsive to brush). A real-time waveform discriminator was used to create and store a template for the action potential evoked in the neuron under study by electrical pulses on the dura; spikes of activity matching the template waveform were acquired and analyzed online and offline using Spike 2 software (Cambridge Electronic Design).

Seizure induction and electrocorticogram recording

Seizures were induced by application of picrotoxin (gelfoam soaked in $10 \mu \mathrm{l}$ of $100 \mathrm{~mm}$ picrotoxin) to the surface of the parietal cortex for the duration of the experiment. This dose was chosen because it consistently induced generalized seizure (i.e., seizure that gave rise to propagating epileptiform activity in all animals). For verification of seizure induction, cortical activity was recorded (ECG) with a glass micropipette $(0.9 \%$ saline, $\sim 1 \mathrm{M} \Omega, 7 \mu \mathrm{m}$ tip) placed at a depth of $\sim 500 \mu \mathrm{m}$ (layers II-III) in the visual cortex. Induction of seizure was confirmed by the appearance of the epileptiform activity in the cortex (Fig. 2A). In order to confirm the method for induction of generalized seizure, preliminary experiments $(n=45)$ were performed in which the propagation of seizure was confirmed by recording epileptiform activity simultaneously in the frontal and occipital cortices (Fig. 2B). As shown in the figure, the typical propagation rate of the epileptiform activity was $0.35 \mathrm{~mm} / \mathrm{min}(0.1-3.3 \mathrm{~mm} /$ $\min )$.

\section{Experimental protocol}

Seizure effects on meningeal nociceptors. A $\delta$ and $\mathrm{C}$ fibers were identified, classified based on their conduction velocities, isolated, and their responses to mechanical indentation of the dura determined. Their firing rate was then recorded for $1 \mathrm{~h}$ before and $2 \mathrm{~h}$ after induction of seizure.

Seizure effects of central trigeminovascular neurons. HT and WDR neurons located in the $\mathrm{SpV}$ were identified by their responses to electrical stimulation of the dura, classified by their responses to innocuous and noxious mechanical stimulation of the skin, and their spontaneous firing was recorded continuously $1 \mathrm{~h}$ before and $2 \mathrm{~h}$ after induction of seizure.

In another set of experiments, lidocaine was applied to the dural receptive field of $\mathrm{A} \delta$ fibers, $\mathrm{C}$ fibers, WDR neurons, and HT neurons for a period of $2 \mathrm{~h}$, starting $1 \mathrm{~h}$ before and ending $1 \mathrm{~h}$ after seizure induction. In these experiments, continuous neuronal recording began $1 \mathrm{~h}$ before and ended $3 \mathrm{~h}$ after seizure induction (i.e., neuronal recording was 

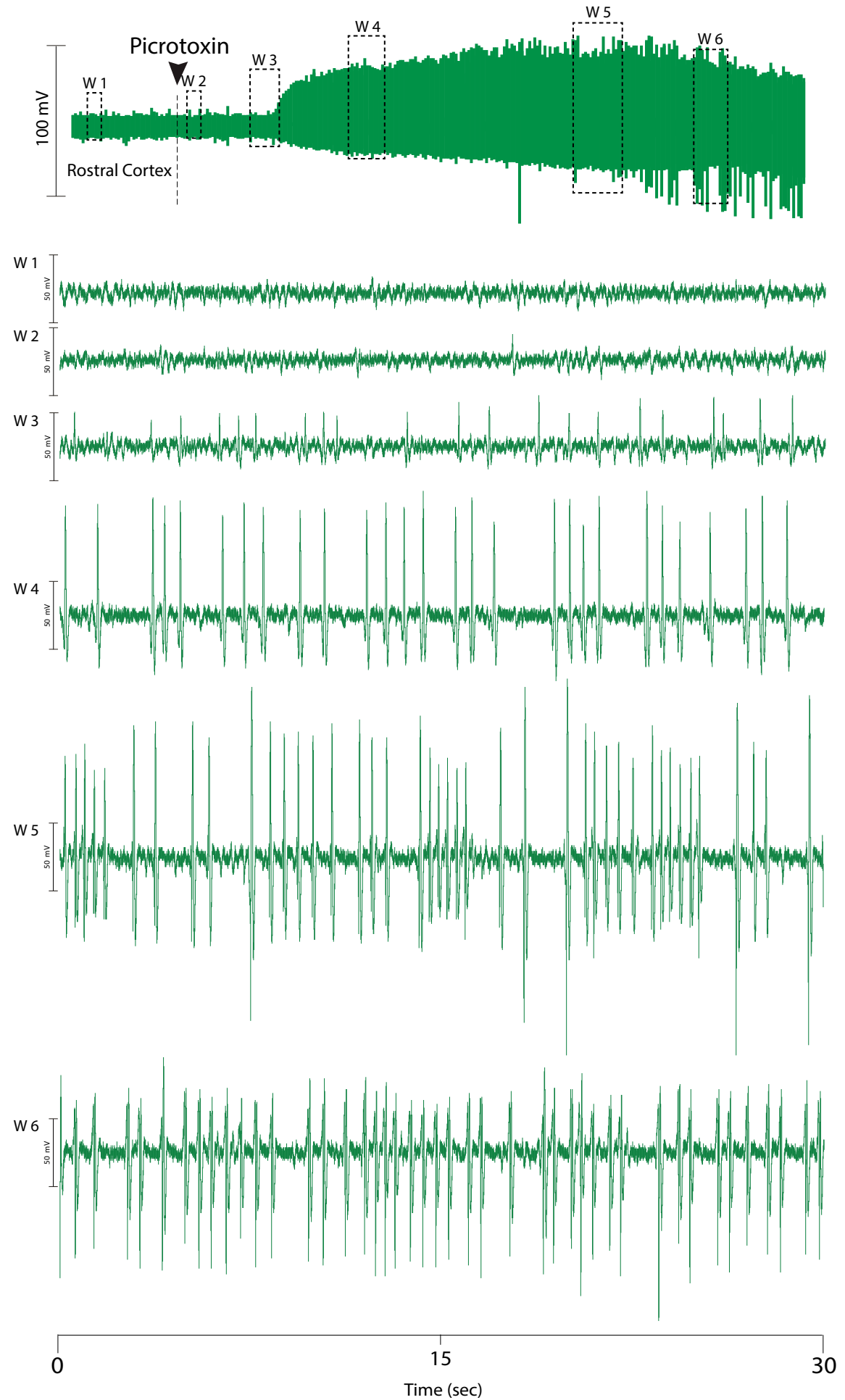

Figure 3. Seizure development from normal (W1) to the appearance of isolated epileptic spikes (W2) and the transition to epileptiform cortical activity characterized by synchronized firing of cortical neurons (W3-W6).

maintained for $2 \mathrm{~h}$ under lidocaine conditions and $2 \mathrm{~h}$ in the absence of lidocaine). neuron was considered activated if its mean firing rate after seizure exceeded its mean baseline activity by $1 \mathrm{SD}$ for a period $>10 \mathrm{~min}$, which translated to $\sim>33 \%$ increase in activity. Mean firing rates of respective values were compared using nonparametric repeated-measures test (Friedman test) and post hoc analysis (Tukey HSD). The level of significance was set at 0.05 . A small number of neurons $(<10 \%)$ showed a brief activation immediately following the picrotoxin application. This brief activation typically subsided before the onset of seizure, and was not included as part of the neuronal response to the seizure. The transient response to picrotoxin is attributable to the DMSO solvent, as found in prior control studies with DMSO application.

\section{Results}

Experiments were conducted in male and female rats. There was no significant difference between males and females in the percentage of neurons that showed seizureinduced activation, in any of the four neuronal groups $(p=0.43, p=0.58, p=0.45$, $p=0.61$, and $\chi^{2}=0.63, \chi^{2}=0.31, \chi^{2}=$ $0.56, \chi^{2}=0.27$ for $\mathrm{A} \delta, \mathrm{C}, \mathrm{WDR}$, and HT, respectively; $\mathrm{df}=1 ; \chi^{2}$ ). Data from males and females were combined for all analyses described below.

\section{Baseline activity}

The firing rate at baseline, before seizure induction was 1.3 spikes/s [0.4-5.7] (median [interquartile range, IQR]) for $\mathrm{A} \delta$, 2.9 spikes/s [0.7-6.1] (median [IQR]) for C, 3.4 spikes/s [0.1-6.6] (median [IQR]) for HT, and 3.5 spikes/s [0.9-10.3] (median [IQR]) for WDR neurons. As noted below, there was no significant difference in baseline firing between neurons that showed seizure-induced activation and those that did not $\left(p=0.72\left(U=17, n_{1}=\right.\right.$ $\left.7, n_{2}=6\right), p=0.59\left(U=23, n_{1}=7, n_{2}=7\right)$, $p=0.91\left(U=149, n_{1}=27, n_{2}=13\right), p=$ $0.97\left(U=29, n_{1}=7, n_{2}=11\right)$ for $\mathrm{A} \delta, \mathrm{C}$, WDR, and HT respectively, MannWhitney).

\section{Seizure characterization}

Seizure was induced successfully in all 85 experiments in which neuronal recording was maintained for the full duration of the experiment. Successful induction of seizure was determined by the transition from normal cortical activity driven by nonsynchronized random firing of cortical neurons (Fig. 3; W1) to epileptiform cortical activity marked by synchronized firing of the cortical neurons (Fig. 3; W3-W6).

\section{Data analysis}

Neuronal activity was analyzed to measure amplitude, latency, and duration of responses to seizure. To determine neuronal responses to seizure, the mean firing frequency occurring before the onset of seizure (calculated from measuring the SA $1 \mathrm{~h}$ before seizure onset) was compared with the mean firing frequency recorded for $1 \mathrm{~h}(0-60 \mathrm{~min}$ after seizure onset) and 2 $\mathrm{h}$ (recorded from 60-120 min after seizure onset) after seizure induction. A

\section{A $\delta$ fiber responses}

Seizure effects were tested on 13 A $\delta$ fibers. Their receptive fields included portions of the dura overlying the visual cortex (Fig. $4 A$ ). Of these, 7 neurons (54\%) were activated by the seizure (Fig. 5AI). Their baseline firing rate (1.6 spikes/s [0.5-7.1] median [IQR]) increased by 0.73 spikes/s $[0.5-1.1]$ at $1 \mathrm{~h}$, and 1.6 
spikes/s [0.6-2.0] at $2 \mathrm{~h}\left(\chi^{2}=11.9, \mathrm{df}=\right.$ $2, p=0.0003$, Friedman test). Post hoc (Tukey HSD) comparisons between baseline and 1 and $2 \mathrm{~h}$ after seizure onset yielded $p$ values of 0.17 and 0.001 , respectively (Fig. 5BI). The latency for activation of these $\mathrm{A} \delta$ fibers, calculated from the time the epileptiform activity was first recorded in the visual cortex to the time the neuronal activity began to increase, was 2.7 [1.0-18.2] min (Fig. 5BII), and the duration of activation was 56.6 [32.0-66.4] min (Fig. 5BIII). In only one of these experiments, neuronal activity was still elevated at the time the recording session ended ( $2 \mathrm{~h}$ after seizure onset). Six $\mathrm{A} \delta$ neurons $(46 \%)$ were not activated by the seizure (Fig. 5AII). Their baseline firing rate (1.0 spikes/s [0.3-5.0]) did not change significantly at $1 \mathrm{~h}$ (decrease of 0.24 spikes/s [0.5-0.03]) or $2 \mathrm{~h}$ (decrease of 0.15 spikes $/ \mathrm{s}[0.31-0.09])\left(\chi^{2}=2.1, \mathrm{df}=2\right.$, $p=0.42$ Friedman test).

\section{C fiber responses}

Seizure effects were tested on 14 C fibers. Their receptive fields included portions of the dura overlying the visual cortex (Fig. 4B). Of these, 7 neurons (50\%) were activated by the seizure (Fig. 6AI). Their baseline firing rate (2.8 spikes/s [1.3-5.1] median [IQR]) increased by 0.4 spikes/s $[-0.2-0.5]$ at $1 \mathrm{~h}$, and 3.2 spikes/s [0.66.2] at $2 \mathrm{~h}\left(\chi^{2}=10.8, \mathrm{df}=2, p=0.001\right.$, Friedman test). Post hoc (Tukey HSD) comparisons between baseline and 1 and $2 \mathrm{~h}$ after seizure onset yielded $p$ values of 0.99 and 0.006 , respectively (Fig. 6BI). The latency for activation of these $\mathrm{C}$ fibers, calculated from the time the epileptiform activity was first recorded in the visual cortex to the time the neuronal activity began to increase, was 11.2 [130.1] min (Fig. 6BII), and the duration of activation was 120 [52.0-120] min (Fig. 5BIII). In four of these experiments, neuronal activity was still elevated at the time the recording session ended ( $2 \mathrm{~h}$ after seizure onset). Seven $\mathrm{C}$ fibers (50\%) were not activated by the seizure (Fig. 6AII). Their baseline firing rate (3.0 spikes/s [0.34-9.26]) did not change significantly at $1 \mathrm{~h}$ (decreased by 0.2 spikes/s [0.60.13 ] or $2 \mathrm{~h}$ (decreased by 0.1 spikes/s [0.1-0.3] $\left(\chi^{2}=5.7, \mathrm{df}\right.$ $=2, p=0.056$ Friedman test).

\section{WDR neuronal responses}

Seizure effects were tested on 40 WDR neurons located in laminae I (16) and V (24) of the SpV (Fig. 7A). Their dural receptive fields included areas anterior to the transverse sinus that overlay the visual cortex (Fig. 7C), and the most sensitive portion of their facial receptive fields was located around the eye (Fig. $7 B$ ). Twenty-seven (11 of 15 lamina I and 16 of 25 lamina V) of these 40 WDR neurons (68\%) were activated by the seizure (Fig. $8 A I$ ). Their baseline firing rate (1.9 spikes/s [0.8-9.8] median [IQR]) increased by 1.4 spikes/s [0.1-6.4] at $1 \mathrm{~h}$, and 4.5 spikes/s [1.108-
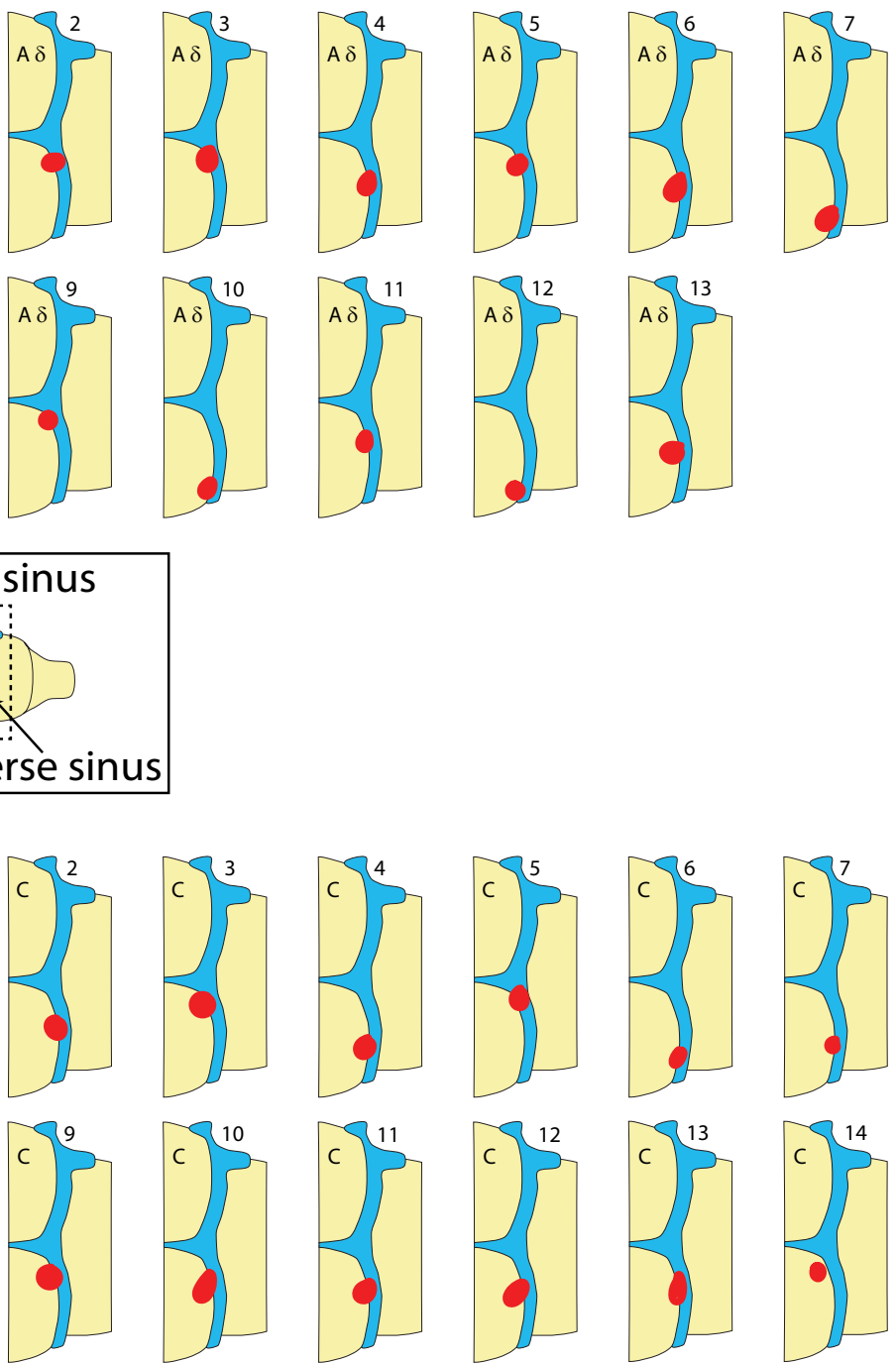

Figure 4. Mechanically sensitive dural receptive fields of $13 \mathrm{~A} \delta$ fibers $(\boldsymbol{A})$ and $14 \mathrm{C}$ fibers $(\boldsymbol{B})$ whose activity was recorded during induction of seizure by picrotoxin. All mechanically sensitive fields on the dura were on or around the transverse sinus. Inset, Dashed line indicates the portion of the dura shown in the receptive field drawings.

10.1] at $2 \mathrm{~h}\left(\chi^{2}=20.6, \mathrm{df}=2, p=0.00,003\right.$, Friedman test $)$. Post hoc (Tukey HSD) comparisons between baseline and 1 and $2 \mathrm{~h}$ after seizure onset yielded $p$ values of 0.015 and 0.004 , respectively (Fig. 8BI). The latency for activation of these WDR neurons was 14.1 [5.7-60] $\mathrm{min}$ (Fig. $8 B I I$ ), and the duration of activation was 98.9 [58.4-120] min (Fig. 8BIII). In 12 of these experiments, neuronal activity was still elevated at the time the recording session ended ( $2 \mathrm{~h}$ after seizure onset). Thirteen WDR neurons $(32 \%)$ were not activated by the seizure (Fig. $8 A I I$ ). Their baseline firing rate (8.8 spikes/s [4.4-12.875]) decreased by 1.1 spikes/s [4.3-0.2] at $1 \mathrm{~h}$, and 1.0 [6.5-0.4] at $2 \mathrm{~h}\left(\chi^{2}=6.5\right.$, $\mathrm{df}=2, p=0.038$ Friedman test). Post hoc (Tukey HSD) comparisons between baseline and 1 and $2 \mathrm{~h}$ after seizure onset yielded $p$ values of 0.095 and 0.007 , respectively.

\section{HT neuronal responses}

Seizure effects were tested on 18 HT neurons located in laminae I (9) and V (9) of the SpV (Fig. 9A). Their dural receptive fields included areas anterior to the transverse sinus that overlay the visual cortex (Fig. 9C), and the most sensitive portion of their facial receptive fields was located around the eye (Fig. 9B). Seven ( 0 of 6 lamina I and 7 of 12 lamina V) of these 18 HT neurons 

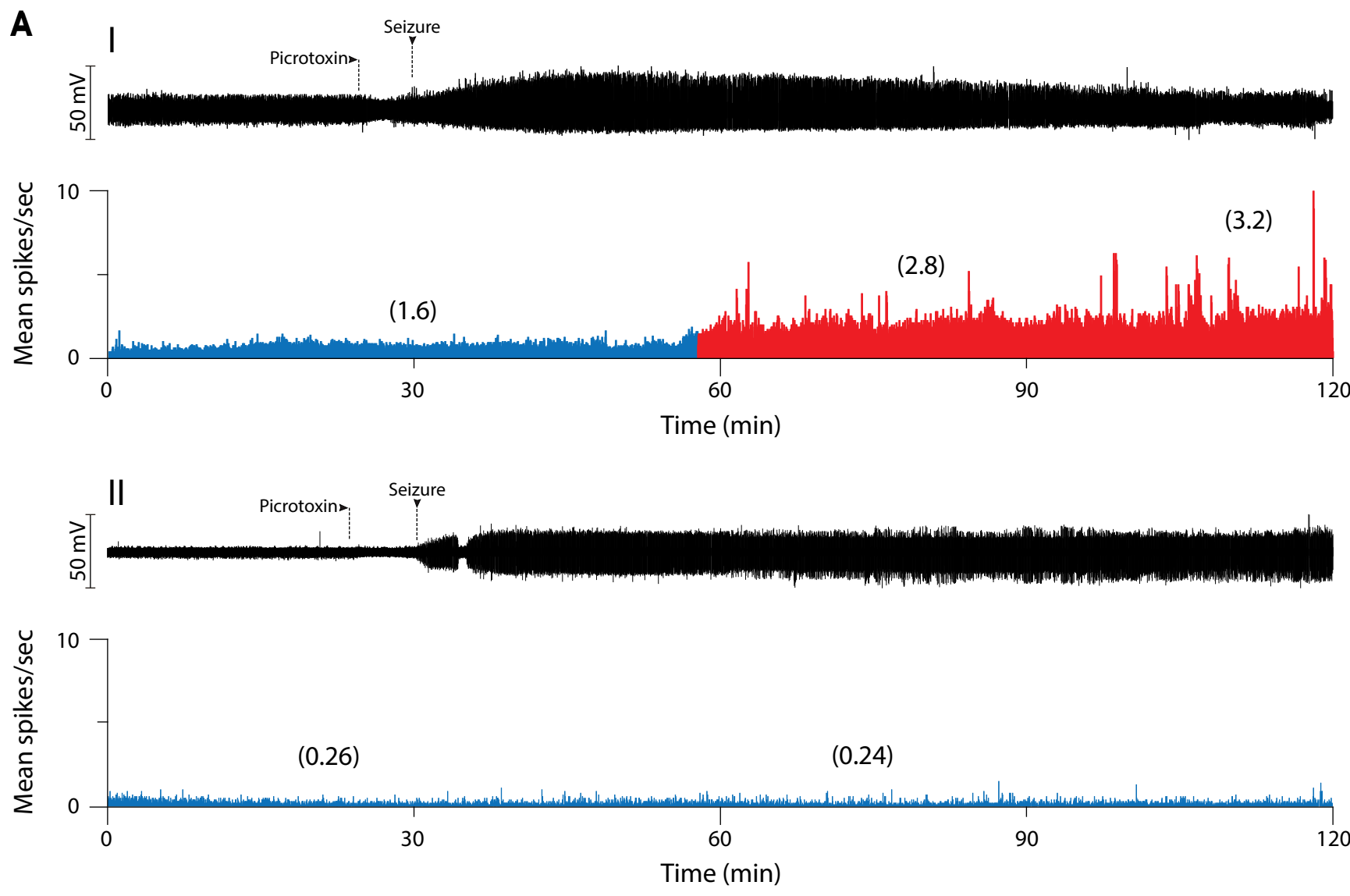

B
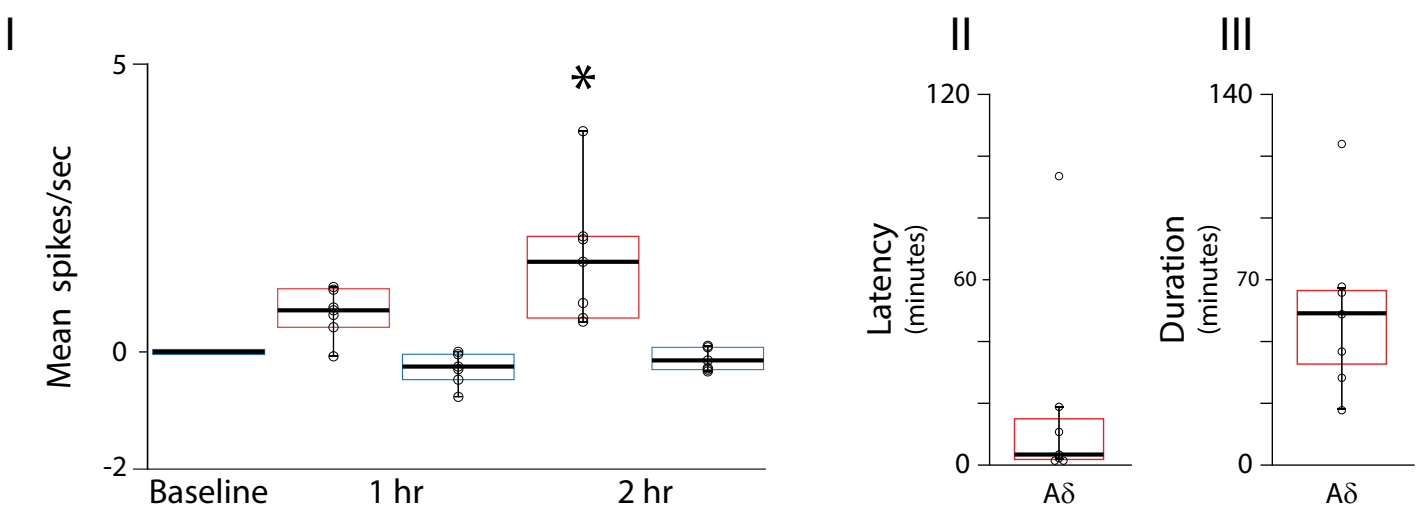

Figure 5. Responses of $A \delta$ fibers to seizure. $A$, Plots of firing rate before and after seizure induction for the following: $(\boldsymbol{A} \boldsymbol{I})$ an $A \delta$ fiber that became activated after induction of epileptic cortical activity; and (AII) an A $\delta$ fiber that did not change its firing rate regardless of the epileptic activity in the cortex. BI, Box-and-whisker plots (median and IQR), as well as scatterplots of individual values, of the changes from baseline at 1 and $2 \mathrm{~h}$ after seizure, in red neurons that became activated $(n=7)$ and in blue neurons that did not get activated ( $n=6)$. ${ }^{*} p<0.05$ (post hoc/Tukey HSD). BII, Box-and-whisker plot of the latency of all neurons activated after seizure induction. BIII, Duration of the activation of said neurons (up to maximum of $2 \mathrm{~h}$, when recording was stopped).

(39\%) were activated by the seizure (Fig. 10AI), all located in lamina V (of note, no lamina I HT neuron was activated). Their baseline firing rate (4.5 spikes/s [1.2-7.3] median [IQR]) increased by 2.9 spikes/s [1.6-7.4] at $1 \mathrm{~h}$, and 8.0 [4.1-11.7] at $2 \mathrm{~h}$ $\left(\chi^{2}=6.8, \mathrm{df}=2, p=0.027\right.$, Friedman test). Post hoc (Tukey HSD) comparisons between baseline and 1 and $2 \mathrm{~h}$ after seizure onset yielded $p$ values of 0.137 and 0.006 , respectively (Fig. $8 B I$ ). The latency for activation of these HT neurons was 6.7 [1.6-31] $\mathrm{min}$ (Fig. 10BII), and the duration of activation was 120 [49.1-120] min (Fig. 10BIII). In four of these experiments, neuronal activity was still elevated at the time the recording session ended ( $2 \mathrm{~h}$ after seizure onset). Eleven HT neurons (61\%) were not activated by the seizure (Fig. 10AII).
Their baseline firing rate (2.6 spikes/s [0-6.5]) showed no significant change at $1 \mathrm{~h}$ (change of 1 spikes/s $[-0.96$ to 0$]$ ) or 2 $\mathrm{h}$ (change of 0 spikes/s $[-3.1$ to 0.7$]\left(\chi^{2}=0.5, \mathrm{df}=2\right.$, $p=0.773$ Friedman test).

\section{Lidocaine effects}

To determine the origin of activation of these trigeminovascular neurons, lidocaine was applied locally to the dura for a period of $2 \mathrm{~h}$ ( $1 \mathrm{~h}$ before and $1 \mathrm{~h}$ after seizure induction). This was tested in 15 central trigeminovascular neurons and 5 trigeminal ganglion neurons. As indicated in Figure 11, lidocaine presence in the dura blocked the activation of $\mathrm{A} \delta$ fibers (Fig. 11A), C fibers (Fig. 11B), WDR neurons (Fig. 11C), and HT neurons (Fig. 
A

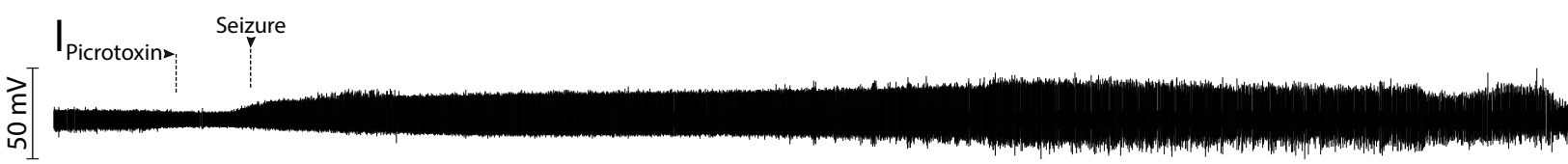

7 0
(1.7)

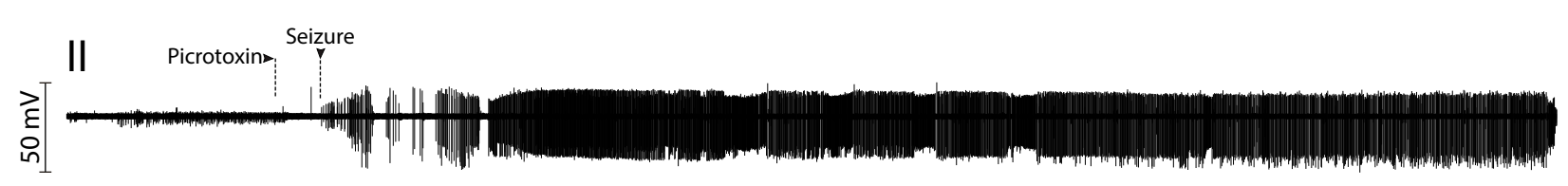

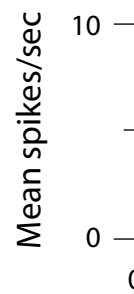

B
(1.7)
60

Time (min)
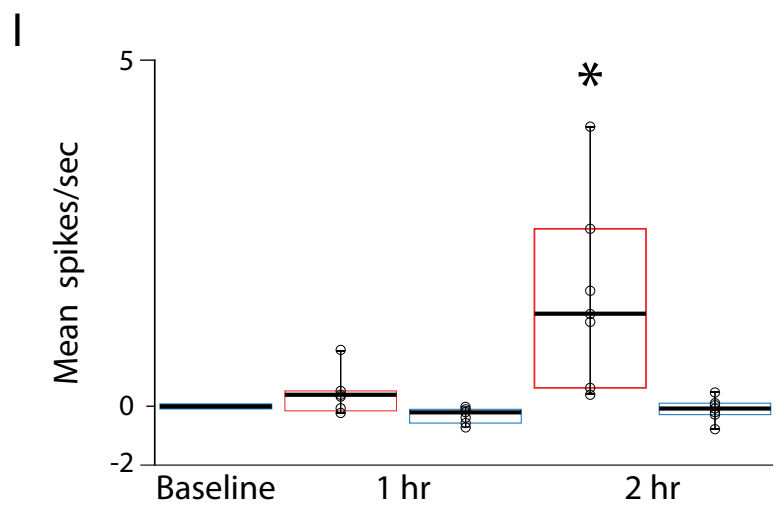

(1.3)
90 120

Time (min) 
A

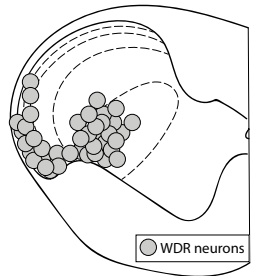

B
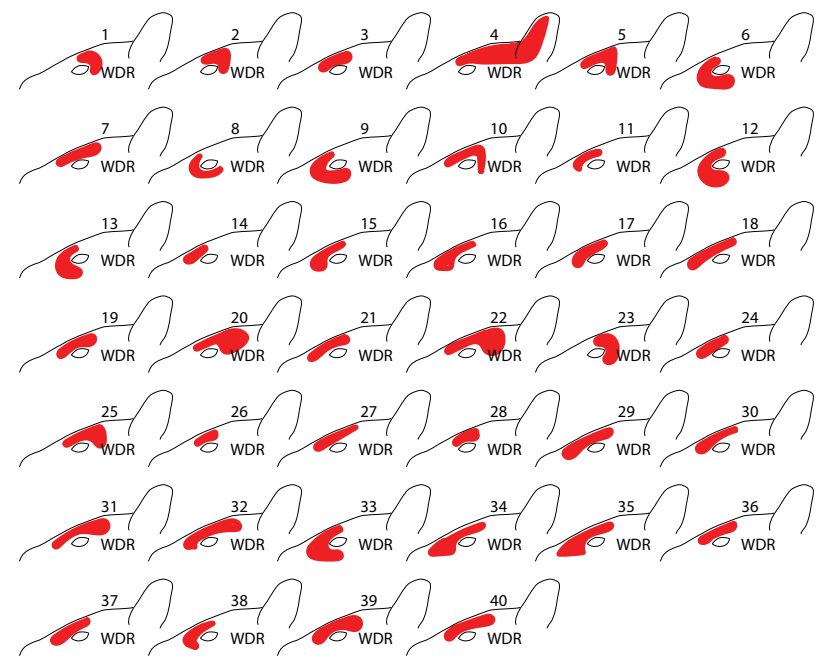

C
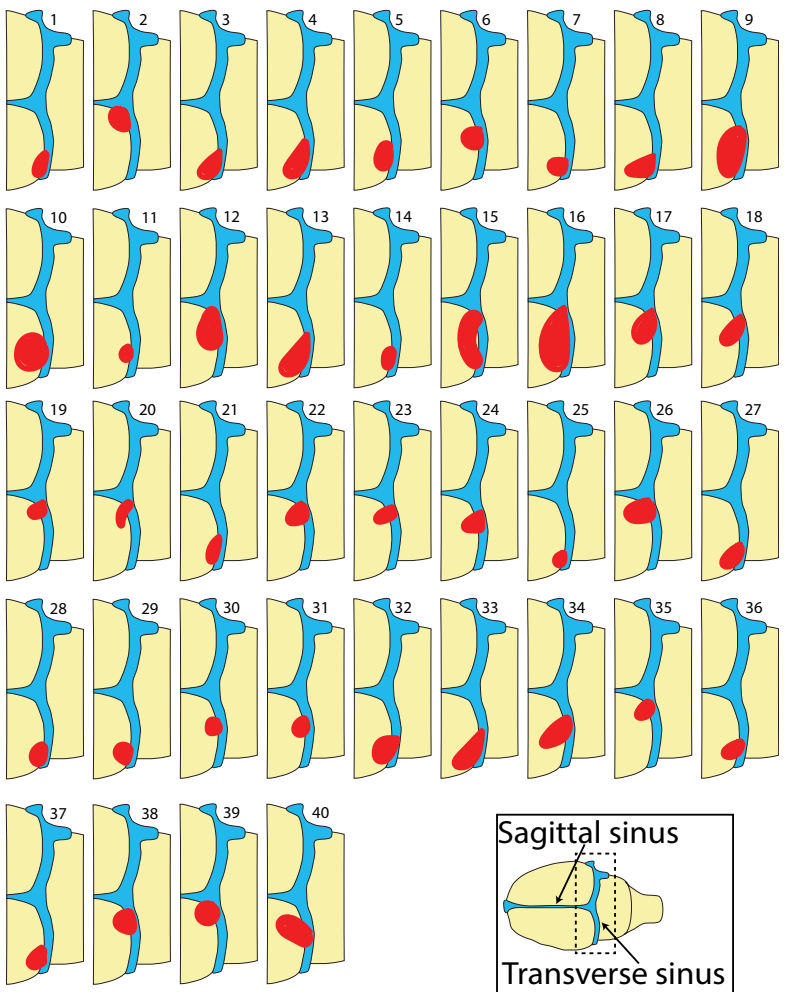

Figure 7. Recording sites $(\boldsymbol{A})$, facial receptive fields $(\boldsymbol{B})$, and dural receptive fields $(\boldsymbol{C})$ of each of the 40 WDR neurons tested for effects after seizure induction. $\boldsymbol{A}$, Recording sites plotted on a representative transverse section through the first cervical segment. Gray circles represent WDR neurons in laminae I and V. $\boldsymbol{B}$, Most sensitive regions of cutaneous receptive field (i.e., where brush, pressure, and pinch were applied). $\boldsymbol{C}$, Mechanically sensitive receptive fields on the dura; all were on or around the transverse sinus. Inset, Dashed line indicates the portion of the dura shown in the receptive field drawings.

of peripheral and central trigeminovascular neurons are involved in the initiation and maintenance of seizureinduced headache. The wide range of activation latencies and duration provide a mechanistic framework for explaining headaches that occur during the seizure itself (called ictal headaches) and those that begin after the seizure had ended (called postictal headache), as well as their brief (just a few minutes) or more prolonged duration. Further mechanistic clues to activation of these four classes of neurons by seizure are provided in experiments showing that application of lidocaine to the dura prevents activation of all classes of peripheral and central trigeminovascular neurons, thus supporting the view that seizure-induced activation of meningeal nociceptors depends on activation of their dural receptors and that the activation of the central neurons depend on inputs they receive from the peripheral nociceptors.

Headaches attributed to epileptic seizures are poorly defined, and their pathophysiologies had not been researched clinically or preclinically. The International Classification of Headache Disorders defines headaches attributed to epileptic seizures as ictal, if they occur during a partial epileptic seizure, involve the ipsilateral head, and remit immediately or soon after the seizure had terminated; and postictal if the headache occurs within $3 \mathrm{~h}$ after the seizure event, and remits spontaneously within $3 \mathrm{~d}$. Based on these definitions, we interpreted cases in which neurons began to fire within minutes (in many cases, as short as $1 \mathrm{~min}$ ) from the occurrence of the epileptic activity as representing a mechanism for initiation of ictal headache, whereas cases in which neurons began to fire an hour or more after occurrence of epileptic activity as representing a mechanism for initiation of postictal headache. Along this line, we propose that neurons that became active immediately after the occurrence of the seizure for a short period of time may represent better the pathophysiology of ictal headache as many such headaches tend to be brief. Mechanistically, neurons whose activity stopped during the seizure suggest that continuing of seizure activity is not sufficient for maintaining neuronal activation. Although our inability to abort the seizure does not allow us to provide further interpretations about the termination of firing while the seizure itself was still going on, the observation itself challenges the view that ictal headaches are short-lasting because they depend on the actual occurrence of the seizure itself. Regarding those cases in which neuronal activity began to increase an hour or more after the occurrence of the epileptic seizure (which in our case was always generalized) and lasted for more than just a few minutes, these may represent better the pathophysiology of postictal headache. This interpretation, however, is also somewhat limited by our inability to abort the seizure without affecting the firing of the nociceptors. If, by definition, postictal seizure can begin only after seizure termination, the delayed activation of the nociceptors and central neurons does not fulfill the current postictal headache criteria. Conversely, our findings suggest that the definition of postictal headache may need to be expanded to the extent that it takes into consideration the possibility that in some cases the headaches can begin during long-lasting seizures.

In general, both the associated symptoms and the headache characteristics that are triggered by epileptic seizures, regardless of whether they are ictal or postictal, are similar to those associated with migraine (Schon and Blau, 1987; Ito et al., 2004; Botha et al., 2010). As with migraine headache 

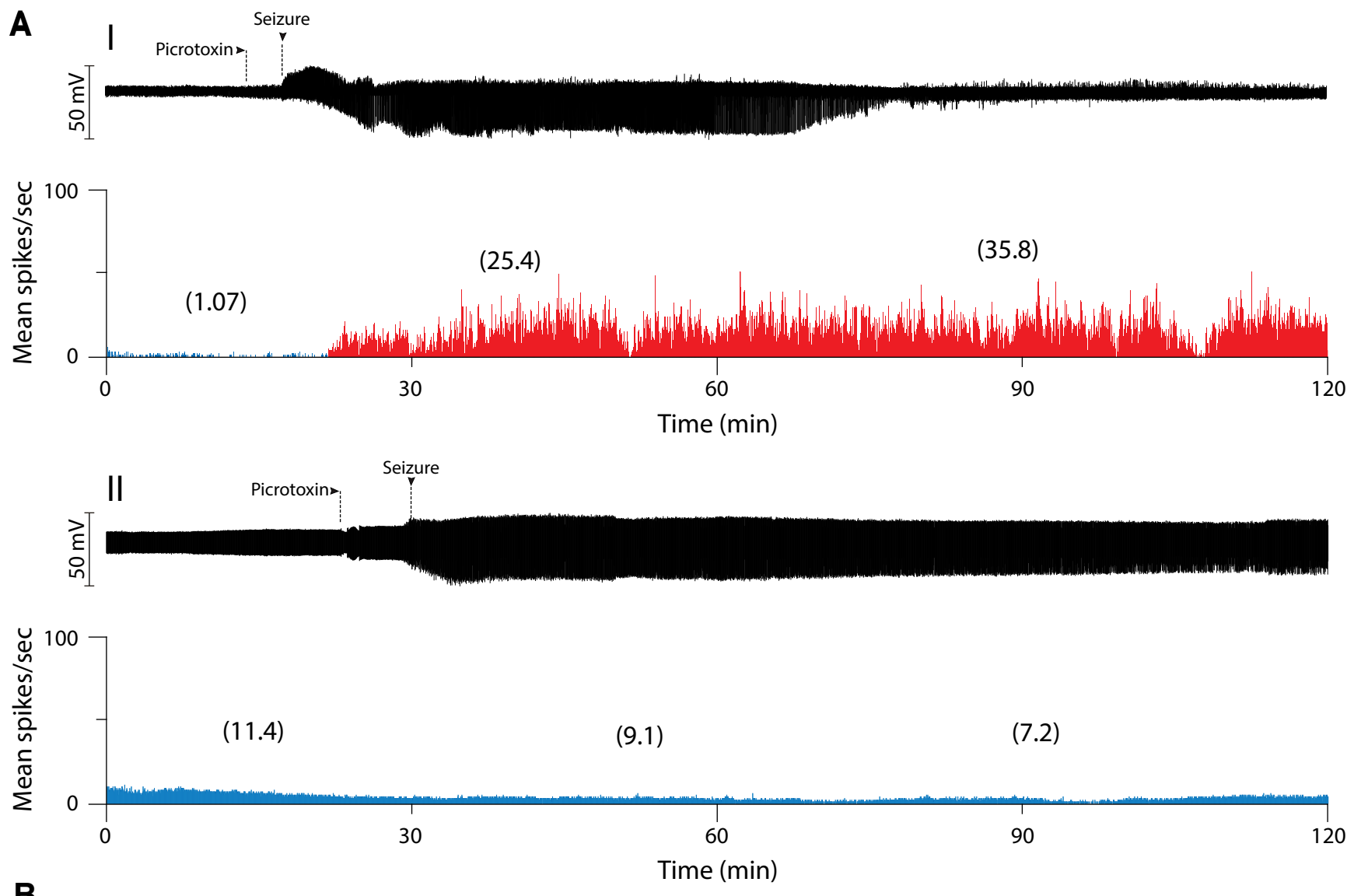

B
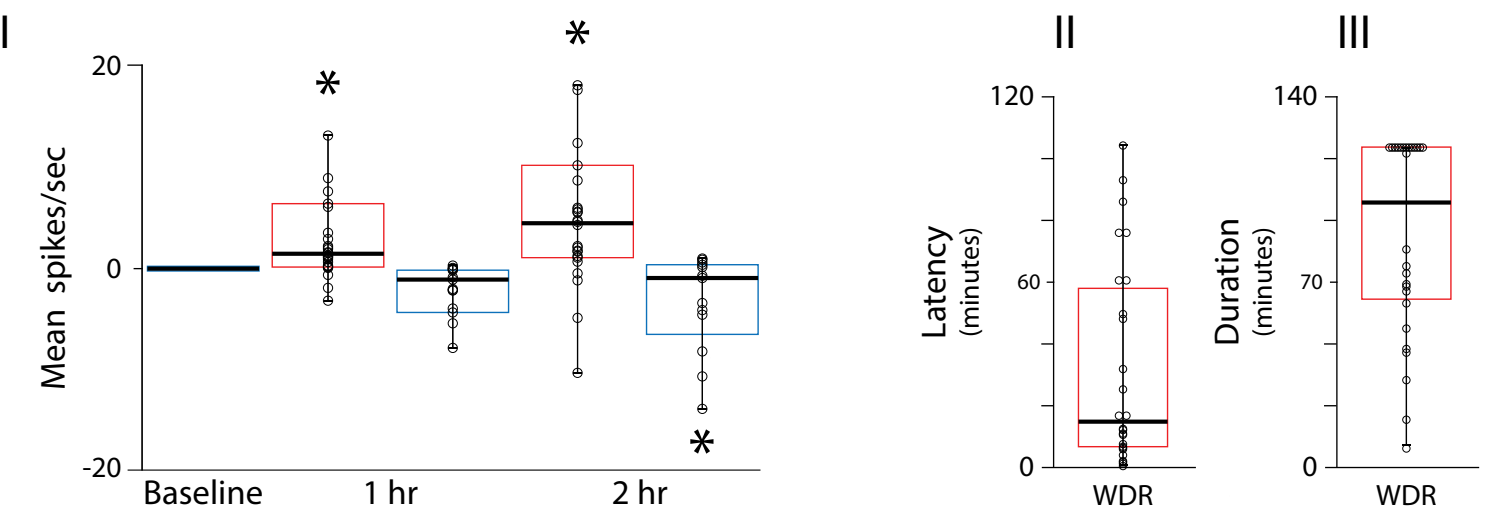

Figure 8. Responses of WDR neurons to seizure. $\boldsymbol{A}$, Plots of firing rate before and after seizure induction for the following: (AI) a WDR neuron that became activated after induction of epileptic cortical activity; and (AII) a WDR neuron that did not change its firing rate regardless of the epileptic activity in the cortex. BI, Box-and-whisker plots (median and IQR), as well as scatterplots of individual values, of the changes from baseline at 1 and $2 \mathrm{~h}$ after seizure, in red neurons that became activated $(n=27)$ and in blue neurons that did not get activated ( $n=13$ ). ${ }^{*} p<0.05$ (post hoc/Tukey HSD). BII, Box-and-whisker plot of the latency of all neurons activated after seizure induction. BIII, Duration of the activation of said neurons (up to maximum of 2 $\mathrm{h}$, when recording was stopped).

(Burstein et al., 2015; Dodick, 2018), ictal and postictal headaches can be moderate or severe, unilateral or bilateral, fronto-orbital and retro-orbital, and described as throbbing, pounding, and exacerbated by sudden head movement (Bernasconi et al., 2001; Caminero and Manso-Calderón, 2014; Fanella et al., 2015). Similarly, their most common associated symptoms include photophobia, phonophobia, vomiting, nausea, and visual hallucination or aura (Ito et al., 1999; Piccioli et al., 2009; Belcastro et al., 2011; Kim and Lee, 2017). These commonalities suggest that the same nociceptive pathways mediate migraine-type and seizure-type headache. Indeed, both migraine and seizure appear to involve activation of meningeal nociceptors and trigemi- novascular neurons in the $\mathrm{SpV}$ from their dural receptive fields (Zhang et al., 2010, 2011). This explanation, while logical, raises the question of how the brain distinguishes between a headache induced by seizure and a headache induced by a migraine event, such as aura or CSD. While the literature focuses heavily on finding all possible similarities between postictal headache and migraine, we must also point out the data that show that $26 \%-56 \%$ of all postictal headaches lack migraine features and in different studies are termed tension-type headache (Leniger et al., 2001), other postictal headache (Ito et al., 2004), or just postictal headache that is not migraine-like (Bernasconi et al., 2001). In the next paragraph, we make the case that the ability to 
A

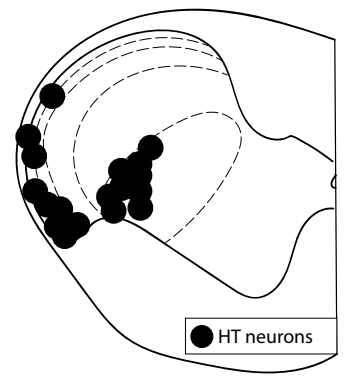

B
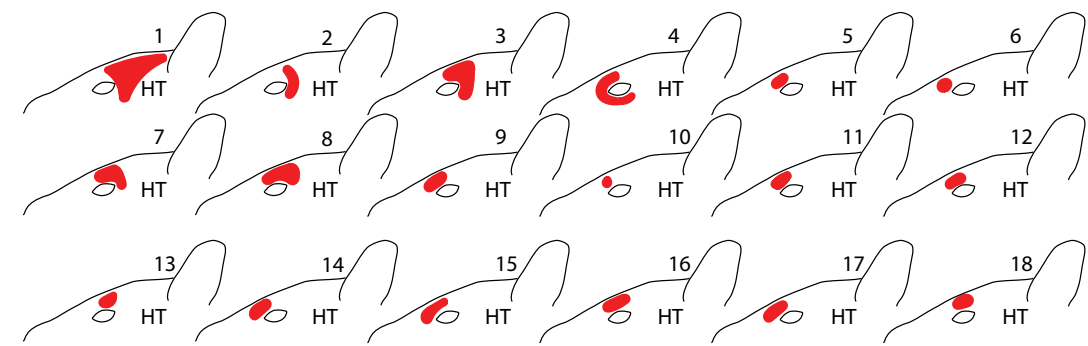

C

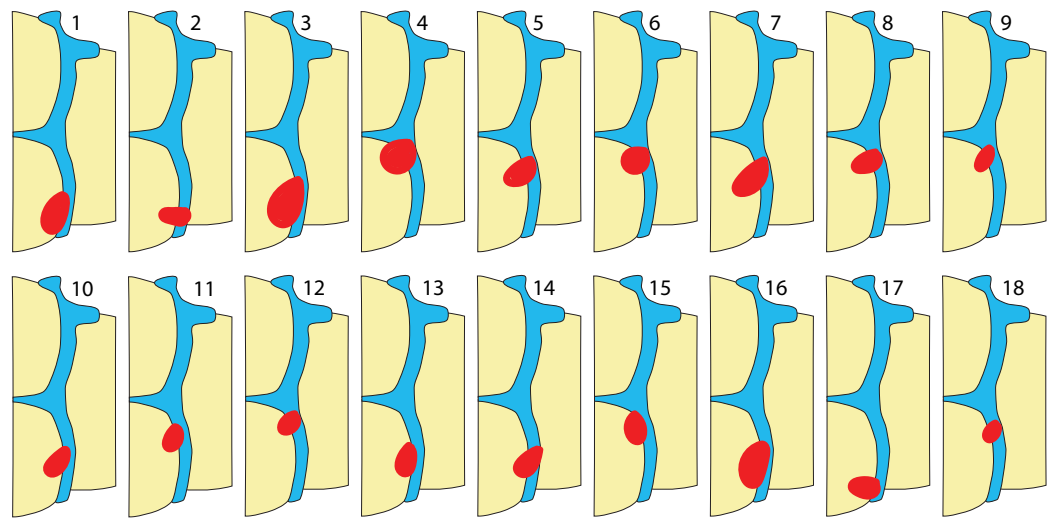

Figure 9. Recording sites $(\boldsymbol{A})$, facial receptive fields $(\boldsymbol{B})$, and dural receptive fields $(\boldsymbol{C})$ of each of the $18 \mathrm{HT}$ trigeminovascular neurons tested for effects after seizure induction. $\boldsymbol{A}$, Recording sites plotted on a representative transverse section through the first cervical segment. Black circles represent HT neurons in laminae I and V. $\boldsymbol{B}$, Most sensitive regions of cutaneous receptive field (i.e., where brush, pressure, and pinch were applied). $\boldsymbol{C}$, Mechanically sensitive receptive fields on the dura; all of them were on or around the transverse sinus. Inset, Dashed line indicates the portion of the dura shown in the receptive field drawings.

distinguish between migraine headache and postictal headache that lack migraine features (Schon and Blau, 1987; Ito et al., 2004; Botha et al., 2010) is generated mainly at supraspinal areas that process nociceptive signals from the meninges with potential contributions from the SpV.

Closer examination of the response characteristics of the different classes of trigeminovascular neurons to CSD (an animal model of migraine headache) and seizure (an animal model of ictal or postictal headache) reveals many similarities and only one difference (Zhang et al., 2010, 2011; Zhao and Levy, 2015, 2018; Melo-Carrillo et al., 2017a,b, 2019). The many similarities include the following: (1) incidence of activation, which was $\sim 50 \%$ in both $\mathrm{A} \delta$ and $\mathrm{C}$ fibers, $40 \%-60 \%$ for WDR, and $30 \%-$ $50 \%$ for HT neurons; (2) duration of activation, which ranged between $10 \mathrm{~min}$ (shortest duration) and $2 \mathrm{~h}$ or more (longest activation we recorded) for all four classes of neurons; (3) latency of activation, which ranged between 1 and $60 \mathrm{~min}$ in all four classes of neurons studies; and (4) magnitude of activation in the peripheral (but not central) neurons, which showed approximately twofold increase for both the $\mathrm{A} \delta$ and $\mathrm{C}$ fibers.
For the central trigeminovascular neurons, magnitude of activation in response to CSD was smaller (twofold for both WDR and HT) than after seizure (fourfold for WDR and threefold for HT). Based on the many similarities and one difference, it is reasonable to propose that it is the central, rather than peripheral, components of the trigeminovascular pathway that allow us to distinguish between a headache induced by seizure and a headache induced by aura or CSD. Along this line, it is reasonable to speculate that a post-seizure cortex processes sensory and nociceptive information (including information from the meningeal sensory pathway) differently than a post-CSD cortex as the two events differ in their ability to alter cortical physiology (spatially, temporally, quantitatively). One finding in the current study that may support this possibility is the larger response magnitude of the central neurons seen after seizure, possibly caused by transient interruption of corticospinal pathways that modulate the activity of ascending nociceptive neurons in the spinal dorsal horn (Noseda et al., 2010).

Mechanistically, one may be tempted to suggest that the massive alteration in the activity of widespread areas of the cortex can, through descending pathways, trigger a headache by causing central trigeminovascular neurons to become activated. In this hypothetical scenario, the activation of the central neurons would not be dependent on input from the primary afferent neurons, and so anesthetic blockade of the dura would be expected to block the seizure response in the primary afferent neurons but not the central neurons. However, this was not the case. Lidocaine application to the dura prevented the activation of the $\mathrm{A} \delta$ and $\mathrm{C}$ fiber primary afferent neurons as well as the WDR and HT central neurons, but not the initiation or maintenance of the seizure. This result confirms that the activation of the central neurons is dependent on primary afferent input and refutes the idea that the seizure-induced activation is via descending pathways.

\section{A note about the validity of this animal model}

Unlike the case of CSD, a phenomenon whose relevance to migraine headache continues to be debated as it cannot be routinely detected clinically, evidence for occurrence of epileptic seizures and ictal or postictal headaches in patients is convincing. By showing that epileptic seizure, an event that occurs inside the blood-brain barrier, is capable of activating meningeal nociceptors from their receptive fields in the dura, which is outside the blood-brain barrier, this study provides an overall justification for the use of these two animal models in the study of headache of intracranial origin. 
A
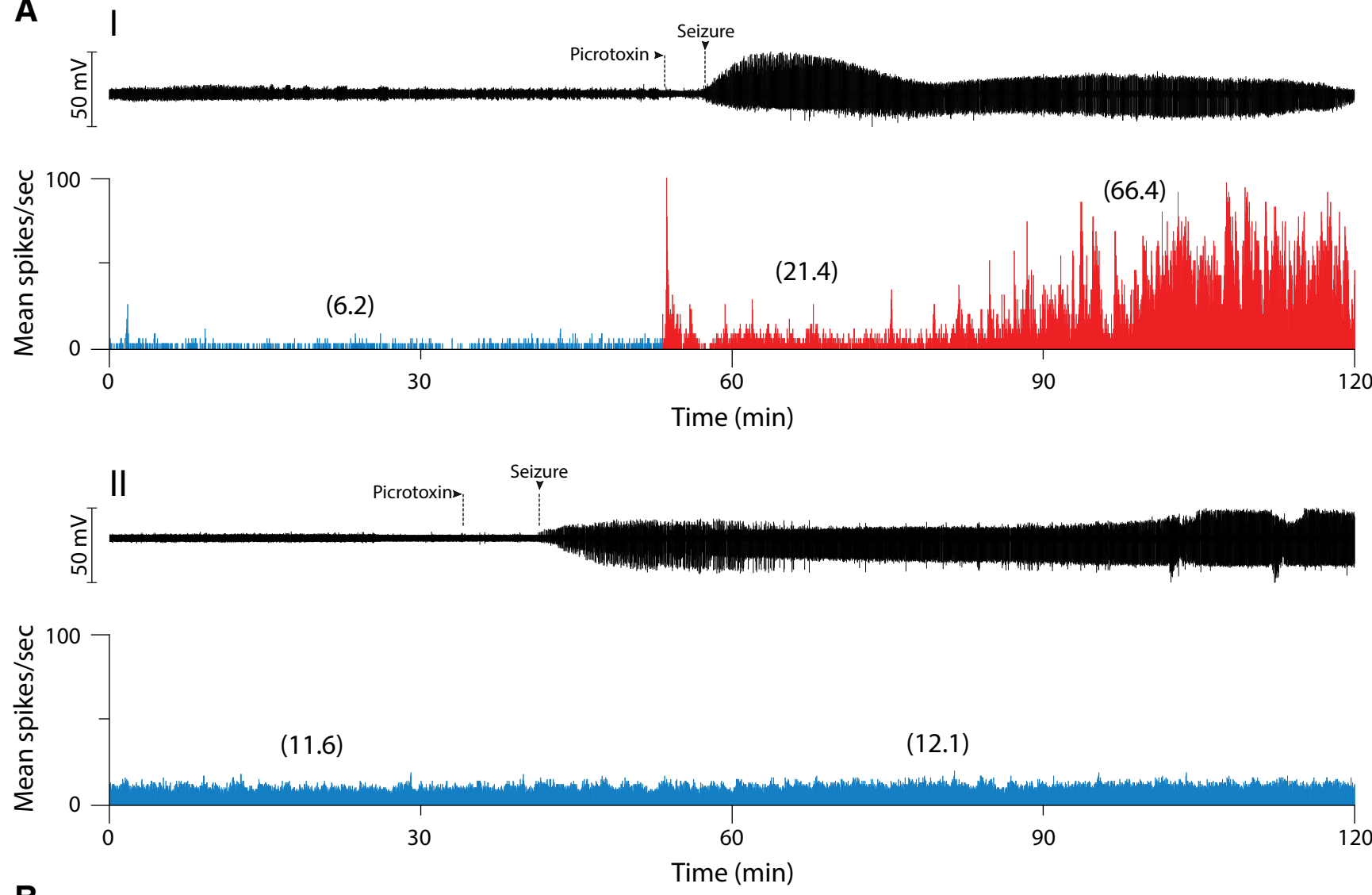

B
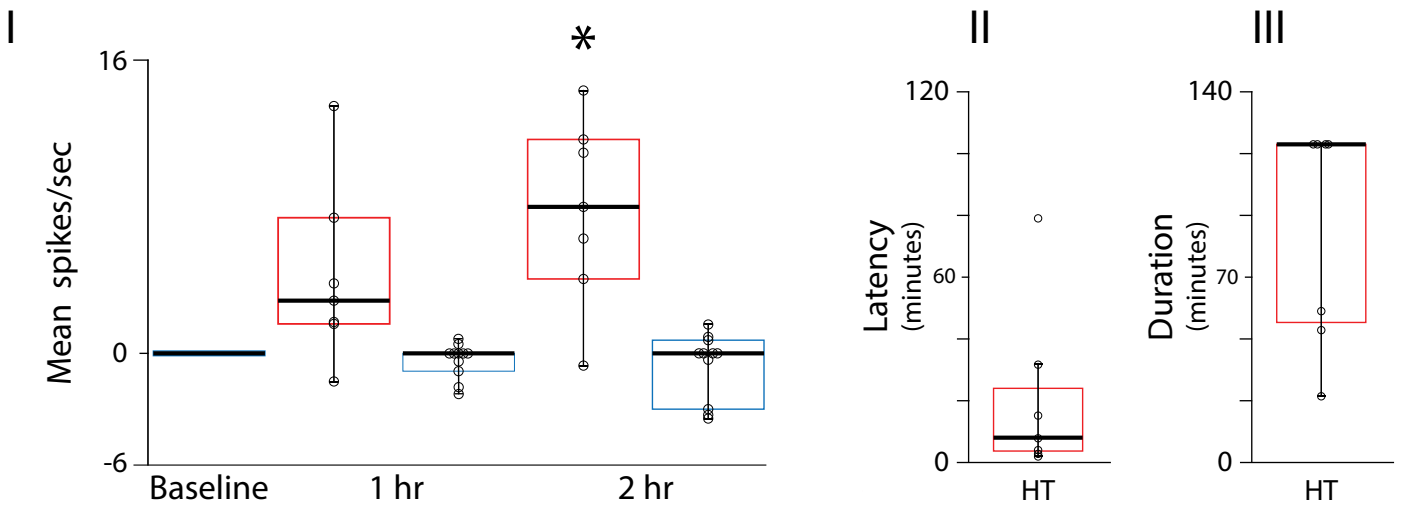

Figure 10. Responses of HT neurons to seizure. $\boldsymbol{A}$, Plots of firing rate before and after seizure induction for the following: (AI) an HT neuron that became activated after induction of epileptic cortical activity; and (AII) an HT neuron that did not change its firing rate regardless of the epileptic activity in the cortex. The neuron in $\boldsymbol{A l}$ showed a brief activation immediately following the picrotoxin application, before the seizure onset; this brief picrotoxin response was present in a small number of neurons $(<10 \%)$, and is attributable to the DMSO solvent, as observed in prior control studies with DMSO application. $\boldsymbol{B I}$, Box-and-whisker plots (median and IQR), as well as scatterplots of individual values, of the changes from baseline at 1 and $2 \mathrm{~h}$ after seizure, in red neurons that became activated $(n=7)$ and in blue neurons that did not get activated $(n=11)$. ${ }^{*} p<0.05$ (post hoc/Tukey HSD). BII, Box-and-whisker plot of the latency of all neurons activated after seizure induction. BIII, Duration of the activation of said neurons (up to maximum of $2 \mathrm{~h}$, when recording was stopped).

\section{Technical considerations and caveats}

Seizure can be induced in rodents by a number of methods, including auditory stimulation, systemic administration of pentylenetetrazole, or electroshock (Loscher, 2011, 2017). For the present study, we chose the method of topical application of picrotoxin to the cortical surface. Although this method requires surgical exposure of the cortex, we found it to be advantageous for our purposes in that we could reliably induce a seizure with consistent characteristics from animal to animal, in a dose-dependent manner. For the present study, we used a dose that produced a generalized seizure, as verified by recording its propagation across the cortex. While we have not tested other methods of seizure induction for activation of meningeal nociceptors, we would expect that such activation would depend on the characteristics of the seizure rather than the method of induction, and so would be similar with any method that induced a generalized cortical seizure.

One caveat that should be recognized in this study, as in all studies of neural activity in the meningeal sensory pathway, is that the surgery that is necessary to expose the neurons' dural receptive 

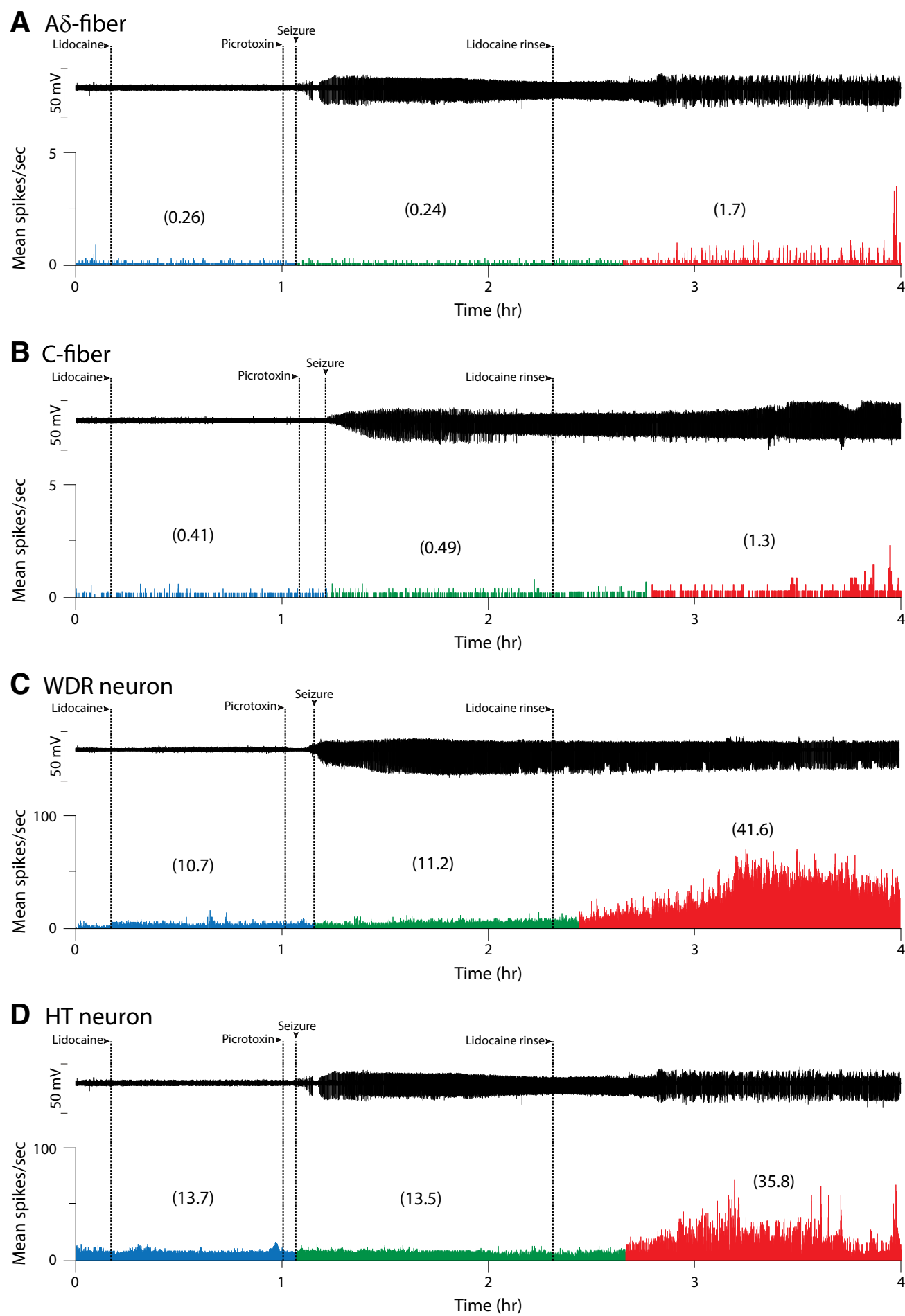

Figure 11. Effect of dural application of lidocaine on neuronal responses to seizure. Plots of firing rate before and after seizure induction of an $A \delta$ fiber $(\boldsymbol{A})$, C fiber $(\boldsymbol{B})$, WDR neuron $(\boldsymbol{C})$, and $\mathrm{HT}$ neuron $(\boldsymbol{D})$. In these experiments, lidocaine was applied locally to the dura for a period of $1 \mathrm{~h}$ before and $1 \mathrm{~h}$ after seizure induction, whereas neuronal recording was maintained for 4 $\mathrm{h}(1 \mathrm{~h}$ before and $3 \mathrm{~h}$ after seizure induction). This experimental setup allowed us to determine the dural role in seizure-induced neuronal activity. In all 4 classes of neurons, the presence of lidocaine in the dura blocked their activation.

fields also produces some disturbance to the exposed dura, as well as damage to the overlying extracranial tissues, which potentially results in some degree of sensitization of the nociceptive innervation. (This caveat applies to virtually all electrophysiological studies of nociceptive sensory pathways.) In our studies, care is taken to minimize the degree of sensitization, including the subcutaneous injection of lidocaine at the incision site. One indication of the degree of sensitization is the level of baseline spontaneous activity, which generally is fairly low in our studies.

\section{References}

Ablah E, Hesdorffer DC, Liu Y, Paschal AM, Hawley S, Thurman D, Hauser WA, Prevalence of Epilepsy in Rural Kansas Study Group (2014) Prevalence of epilepsy in rural Kansas. Epilepsy Res 108:792-801. 
Belcastro V, Striano P, Kasteleijn-Nolst Trenité DG, Villa MP, Parisi P (2011) Migralepsy, hemicrania epileptica, postictal headache and "ictal epileptic headache": a proposal for terminology and classification revision. J Headache Pain 12:289-294.

Bernasconi A, Andermann F, Bernasconi N, Reutens DC, Dubeau F (2001) Lateralizing value of peri-ictal headache: a study of 100 patients with partial epilepsy. Neurology 56:130-132.

Botha SS, Schutte CM, Olorunju S, Kakaza M (2010) Postictal headache in South African adult patients with generalised epilepsy in a tertiary care setting: a cross-sectional study. Cephalalgia 30:1495-1501.

Burstein R, Noseda R, Borsook D (2015) Migraine: multiple processes, complex pathophysiology. J Neurosci 35:6619-6629.

Burstein R, Yamamura H, Malick A, Strassman AM (1998) Chemical stimulation of the intracranial dura induces enhanced responses to facial stimulation in brain stem trigeminal neurons. J Neurophysiol 79:964-982.

Caminero A, Manso-Calderón R (2014) Links between headaches and epilepsy: current knowledge and terminology. Neurologia 29:453-463.

Cianchetti C, Pruna D, Ledda M (2013) Epileptic seizures and headache/migraine: a review of types of association and terminology. Seizure 22:679685.

Dado RJ, Katter JT, Giesler GJ Jr (1994) Spinothalamic and spinohypothalamic tract neurons in the cervical enlargement of rats: II. Responses to innocuous and noxious mechanical and thermal stimuli. J Neurophysiol 71:981-1002.

Dodick DW (2018) A phase-by-phase review of migraine pathophysiology. Headache 58 Suppl 1:4-16.

Fanella M, Morano A, Fattouch J, Albini M, Casciato S, Manfredi M, Giallonardo AT, Di Bonaventura C (2015) Ictal epileptic headache revealing non convulsive status epilepticus in a case of eyelid myoclonia with absences. J Headache Pain 16:105.

Fiest KM, Sauro KM, Wiebe S, Patten SB, Kwon CS, Dykeman J, Pringsheim T, Lorenzetti DL, Jette N (2017) Prevalence and incidence of epilepsy: a systematic review and meta-analysis of international studies. Neurology 88:296-303.

Forderreuther S, Henkel A, Noachtar S, Straube A (2002) Headache associated with epileptic seizures: epidemiology and clinical characteristics. Headache 42:649-655.

Headache Classification Committee of the International Headache Society (2018) The International Classification of Headache Disorders, 3rd edition. Cephalalgia 38:1-211.

Ito M, Nakamura F, Honma H, Takeda Y, Kobayashi R, Miyamoto T, Koyama T (1999) A comparison of postictal headache between patients with occipital lobe epilepsy and temporal lobe epilepsy. Seizure 8:343346.

Ito M, Adachi N, Nakamura F, Koyama T, Okamura T, Kato M, Kanemoto K, Nakano T, Matsuura M, Hara S (2004) Characteristics of postictal headache in patients with partial epilepsy. Cephalalgia 24:23-28.

Karaali-Savrun F, Goksan B, Yeni SN, Ertan S, Uzun N (2002) Seizure-related headache in patients with epilepsy. Seizure 11:67-69.

Kim DW, Lee SK (2017) Headache and epilepsy. J Epilepsy Res 7:7-15.

Kwan P, Man CB, Leung H, Yu E, Wong KS (2008) Headache in patients with epilepsy: a prospective incidence study. Epilepsia 49:1099-1102.

Leniger T, Isbruch K, von den Driesch S, Diener HC, Hufnagel A (2001) Seizure-associated headache in epilepsy. Epilepsia 42:1176-1179.

Loscher W (2011) Critical review of current animal models of seizures and epilepsy used in the discovery and development of new antiepileptic drugs. Seizure 20:359-368.

Loscher W (2017) Animal models of seizures and epilepsy: past, present, and future role for the discovery of antiseizure drugs. Neurochem Res 42:1873-1888
Melo-Carrillo A, Strassman AM, Nir RR, Schain AJ, Noseda R, Stratton J, Burstein R (2017a) Fremanezumab-A humanized monoclonal antiCGRP antibody inhibits thinly myelinated (Adelta) but not unmyelinated (C) meningeal nociceptors. J Neurosci 37:10587-10596.

Melo-Carrillo A, Noseda R, Nir RR, Schain AJ, Stratton J, Strassman AM, Burstein R (2017b) Selective inhibition of trigeminovascular neurons by fremanezumab: a humanized monoclonal anti-CGRP antibody. J Neurosci 37:7149-7163.

Melo-Carrillo A, Strassman AM, Schain AJ, Noseda R, Ashina S, Adams A, Brin MF, Burstein R (2019) Exploring the effects of extracranial injections of botulinum toxin type A on prolonged intracranial meningeal nociceptors responses to cortical spreading depression in female rats. Cephalalgia 39:1358-1365

Moskowitz MA (1984) The neurobiology of vascular head pain. Ann Neurol 16:157-168.

Murray CJ, Vos T, Lozano R, Naghavi M, Flaxman AD, Michaud C, Ezzati M, Shibuya K, Salomon JA, Abdalla S, Aboyans V, Abraham J, Ackerman I, Aggarwal R, Ahn SY, Ali MK, Alvarado M, Anderson HR, Anderson LM, Andrews KG, et al. (2012) Disability-adjusted life years (DALYs) for 291 diseases and injuries in 21 regions, 1990-2010: a systematic analysis for the Global Burden of Disease Study 2010. Lancet 380:2197-2223.

Noseda R, Constandil L, Bourgeais L, Chalus M, Villanueva L (2010) Changes of meningeal excitability mediated by corticotrigeminal networks: a link for the endogenous modulation of migraine pain. $J$ Neurosci 30:14420-14429.

Palecek J, Paleckova V, Dougherty PM, Carlton SM, Willis WD (1992) Responses of spinothalamic tract cells to mechanical and thermal stimulation of skin in rats with experimental peripheral neuropathy. J Neurophysiol 67:1562-1573.

Piccioli M, Parisi P, Tisei P, Villa MP, Buttinelli C, Kasteleijn N, Trenite DG (2009) Ictal headache and visual sensitivity. Cephalalgia 29:194-203.

Sanchez Fernandez I, Stephen C, Loddenkemper T (2017) Disparities in epilepsy surgery in the United States of America. J Neurol 264:1735-1745.

Schon F, Blau JN (1987) Post-epileptic headache and migraine. J Neurol Neurosurg Psychiatry 50:1148-1152.

Strassman AM, Raymond SA, Burstein R (1996) Sensitization of meningeal sensory neurons and the origin of headaches. Nature 384:560-564.

Syvertsen M, Helde G, Stovner LJ, Brodtkorb E (2007) Headaches add to the burden of epilepsy. J Headache Pain 8:224-230.

Verducci C, Hussain F, Donner E, Moseley BD, Buchhalter J, Hesdorffer D, Friedman D, Devinsky O (2019) SUDEP in the North American SUDEP Registry: the full spectrum of epilepsies. Neurology 93:e227-e236.

Yankovsky AE, Andermann F, Bernasconi A (2005) Characteristics of headache associated with intractable partial epilepsy. Epilepsia 46:1241-1245.

Zarrelli MM, Beghi E, Rocca WA, Hauser WA (1999) Incidence of epileptic syndromes in Rochester, Minnesota: 1980-1984. Epilepsia 40:1708-1714.

Zhang X, Levy D, Noseda R, Kainz V, Jakubowski M, Burstein R (2010) Activation of meningeal nociceptors by cortical spreading depression: implications for migraine with aura. J Neurosci 30:8807-8814.

Zhang X, Levy D, Kainz V, Noseda R, Jakubowski M, Burstein R (2011) Activation of central trigeminovascular neurons by cortical spreading depression. Ann Neurol 69:855-865.

Zhao J, Levy D (2015) Modulation of intracranial meningeal nociceptor activity by cortical spreading depression: a reassessment. J Neurophysiol 113:2778-2785

Zhao J, Levy D (2018) The CGRP receptor antagonist BIBN4096 inhibits prolonged meningeal afferent activation evoked by brief local $\mathrm{K}(+)$ stimulation but not cortical spreading depression-induced afferent sensitization. Pain Rep 3:e632. 